\title{
THE PRACTICAL VALUE OF THE ELECTROENCEPHALOGRAM DURING ANAESTHESIA
}

\section{E. A Garn, M.D. ${ }^{1}$}

The INTRODUCTion of a wide variety of anaesthetic agents, the develorment of many new and complex technıques, and the ever increasing magnitude o: surgical procedure have so altered the practice of clinical anaesthesia that the traditional concepts of the signs of anaesthetic depth are no longer adequate or accurate. The scheme for the clinical signs of anaesthesia elaborated by Guedel (1) based upon the progressive disappearance of reflex responses, and similar schemes listing signs for intravenous agents are of httle value in assessing the patient anaesthetzed by modern drug combinations and techniques. It has become impossible to formulate the signs of anaesthesia for every set of circurnstances now likely to be encountered, and the "semi-intultive assessment" of the patient by such unreliable monitors as the "educated hand," and the crrculalory variations are far from accurate. The need for a reliable means of accurately and continuously assessing the depth and rellex responsiveness of the patient is more important than ever before Only the electroencephalogram provides the accurate quantitative assessment that is required, in that it provides a continuous record of the extent to which the electrical activity of the patient's brain is being affected. In this way it provides an accurate measurement of the blood level and brain depression of the patient (3) In addition the electroencephalogram promptly reveals changes in cerebral activity due to alterations in cerebral circulation or metabolism precipitated by anaesthetic complication or surgical interference. As a result, this monitor is gainung increasing acceptance and importance.

A large literature is accumulating on the use of the electroencephalogram during anaesthesia and clearly delineated patterns (Fig 1) for the more frequently used agents have been described $(2,3,4,5)$. The electroencephalogram is based on the physiological fact that a whole mass of cortical cells discharges synchronously at approximately the same rate and for this reason the pattern is one of a recurring rhythm; whereas, if the discharge was asynchronous and at different rates, the record would consist of an irregular pattern as is seen with mental and visual activity. The resting discharge is due to the existence of a circuit between the cortex and thalamus Impulses from the cord and cortex reach the thalamus causing the thalamus to discharge, which in turn stimulates the cortex again.

In the deeper levels of anaesthesia, the cortical potentials occur in groups separated by periods of inactivity. Stımulation of the thalamus during one of these periods can set up typical alpha waves in the cortex. These findings suggest that at the level of anaesthesia associated with periods of suppression of cortical activity, there must be a depression at some point in the cortico-thalamic circuit.

1Department of Anaesthesia, University of Alberta Hospital and Faculty of Medicine, Unversity of Alberta, Edmonton, Alta. 
As the cortex remains capable of responding to normal stumuli, this depression must occur at the thalamic level or below: that is, the thalamus is not capable of responding to its normal stımulus or thalamic activity is normal, but the stmul are unable to reach it.

For purposes of anaesthesia only unilateral leads are required. Under anaesthesia the individual wide variation disappears, even in patients with abnormal patterns, which greatly simplifies the use of the electroencephalogram during anaesthesia (6). As anaesthesia deepens, an orderly progression of changing patterns occurs These special patterns vary depending on the agent being used They are not affected by relaxants or by opıates in usual clnical doses. Many other factors such as hypercapnia, hypocaprua, hypoxia and hyperglycemia can affect the pattern and must be excluded, nevertheless, during clinical anaesthesia as usually conducted the only signuficant factor is the brain content of the anaesthetic agent and the tracing obtained is drrectly related to the concentration of the agent in the brain $(6,7)$.

It is now a well-recognized fact that the clinical signs of anaesthesia lag behind the electroencephalographic levels and it is necessary to consider the phase of anaesthesia, whether it be induction, mantenance, or emergence, when interpreting the signs, this "lag phenomenon" can lead to dangerous blood levels is some poor risk patients if only clinical signs are relied on (7). This technique of monitoring was first used primarily as a research tool to obtain and maintain comparable anaesthetic levels during investigative procedures. With the introduction of cardiac surgery and the extreme care necessary to avold overdose, which is so poorly tolerated by these patients, the value of the electroencephalogram became apparent (8).

When extracorporeal curculation was instituted, it was believed that some monitoring device was necessary to detect any serious deficiency in the cerebral crrculation which could cause irreversible cerebral damage The need for accurate monitoring of anaesthetic depth was also as essential in open-heart surgery as in closed.

We are aware that many large centres doing a large amount of this type of cardiac surgery do not use or beheve that there is any need for electroencephalographic monitoring. We would agree that where possible simplicity is desirable and therefore looked into the possibility of abandoning another piece of equipment in an already overcrowded theatre. We attempted to discover to what extent it had been of help in avolding complications or had been of value in other aspects of anaesthesia and surgery

\section{OVERDOSE}

As mentioned previously the clinical signs frequently lag behind the electroencephalographic levels The clinical signs often indicate actuve reflex response when the electroencephalographic level indicates adequate depth for surgery (7) Evidently time is required for brain and tissue equilibrium to be reached Simlarly with emergence a waking pattern does not always mean a responsive 
EXAMRES OF BRAIN WAYNAS AFFECTED BY VARIOUS ANESTHETKS

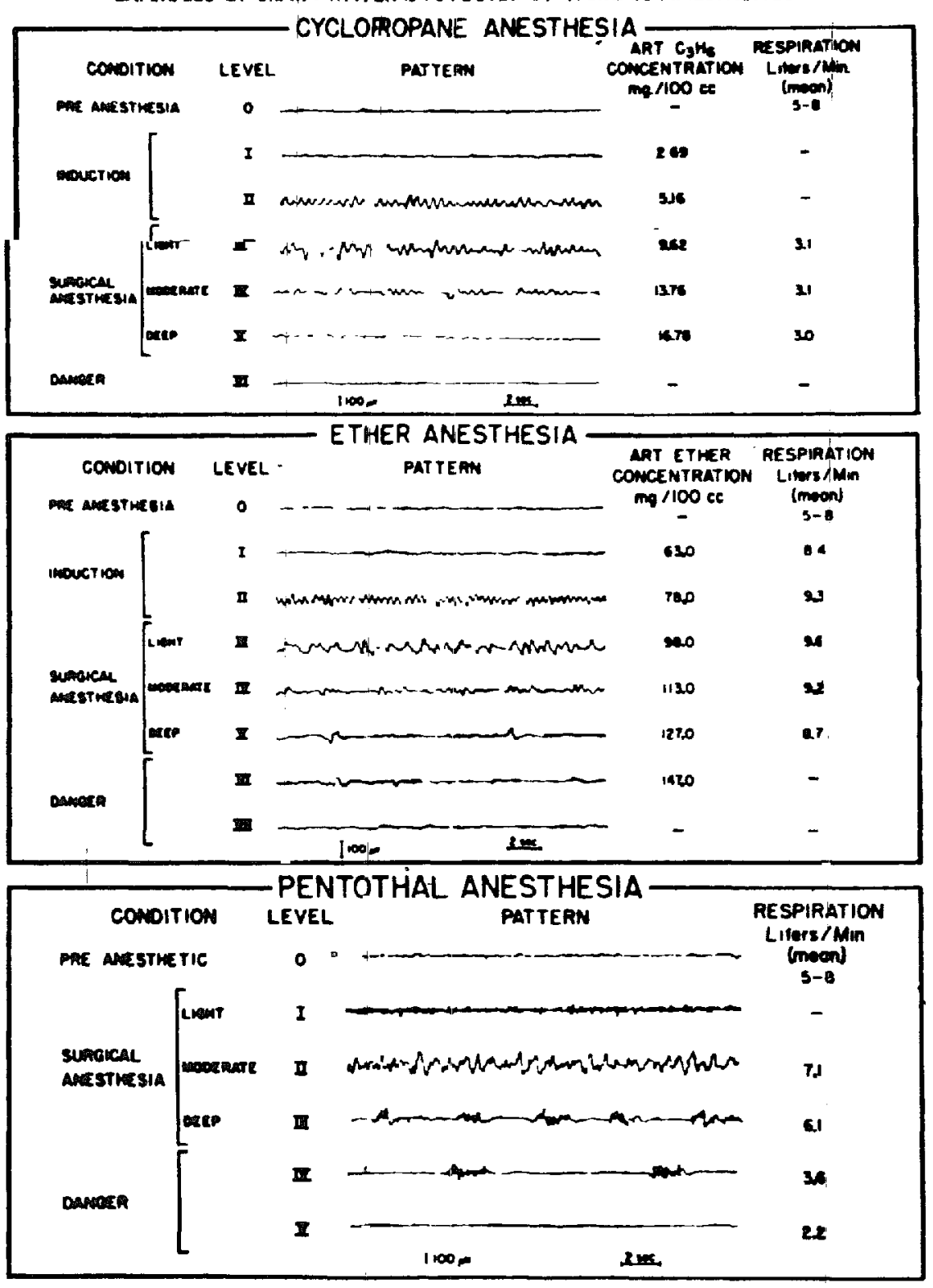

Figure 1

patient at the close Because of this lag a few cases of rather sudden and severe cardiovascular depression have occurred in our cardiac work when the anaesthetsst believed that the patient was in a very light plane of anaesthesia, but the electroencephalographic level was invariably too deep for this type of cardiac patient We now believe that continuous monitoring is worthwhile in this type of case, at least untıl equilibrium has been achieved.

Figure 2 illustrates an electroencephalogram during induction in a case of ventricular septal defect The patient was clinically light and reflexly responsive but had a blood pressure of 50 systolic which the resident refused to beheve 


\section{B.P. $110 \%$ \\ Post Induction}

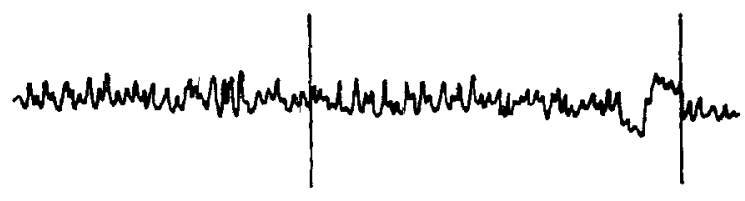

BP. $\frac{50}{20}$
Active Reflexes

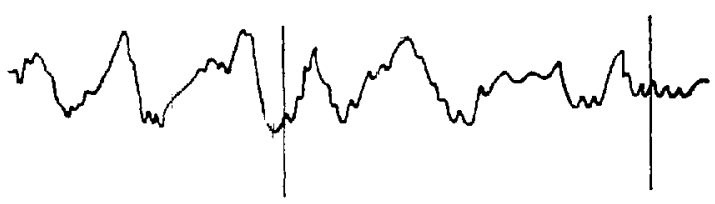

B.P. $\frac{100}{70}$

4 Mins later

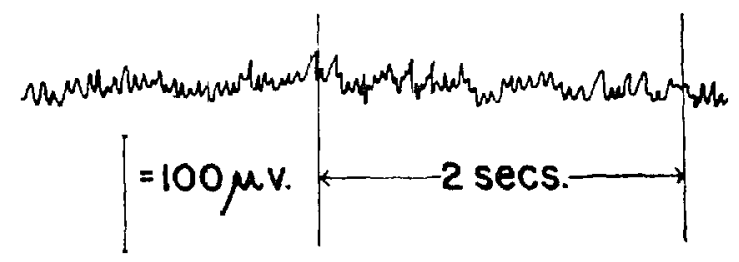

\section{Ether "Lag Phenomena" - Ventricular Septal Defect}

\section{Over Dose.}

Ficure 2

was due to overdose untıl he was shown the electroencephalogram. With washout of the ether the electroencephalographic level returned to level 2 and with it the blood pressure Often in infants clinucal methods of blood pressure determmation are very difficult or impossible to obtain, and in the poor risk infant this monitor can be very useful in protecting agamst anaesthetic overdose.

\section{Extracorporeal Circulation}

It is in this type of work that the electroencephalograph is of most frequent help in protecting the patient against the hazards of anaesthesia and extracorporeal circulation. We have frequently seen, when using the "bubble oxygenator and sigma motor pump," that with commencement of the perfusion, after the caval catheters are clamped, rapid deterioration of the electroencephalogram occurs. Usually in these cases there is a rise in venous pressure to $15-30 \mathrm{~mm}$. $\mathrm{Hg}$ and the head becomes very congested in appearance. If the perfusion continues, all electrical activity may cease. When this occurs, a return to normal circulation is made, the venous catheters are readjusted if necessary, and another attempt is made As a result, it is possible that several potential cases of cerebral damage have been avolded. The usual changes seen are shown in Figure 3.

Occasionally, the very same pattern will occur but without any evidence of increase in venous pressure. In the case shown in Figure 4, a venous pressure tracing could not be obtained and congestion was not apparent. The encephalo- 
Pre Perfusion

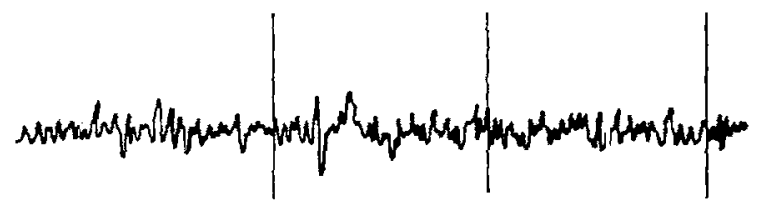

Perfusion Imin. Perfusion Imin.
Venous Press $30 \mathrm{mmH}$.
Head Congested

Normal Circulation restored 2 mins.

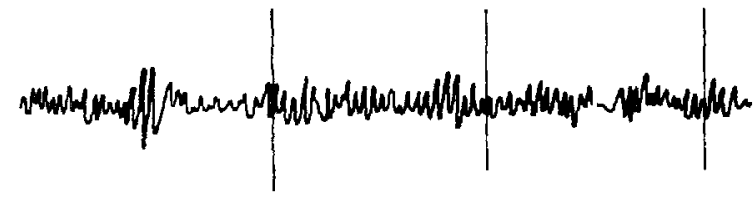

2nd. Perfusion 5 Minutes.<smiles>CCNC(C)(C)CC(C)(C)CC(C)(C)C</smiles>

2nd Perfusion
25 Minutes.

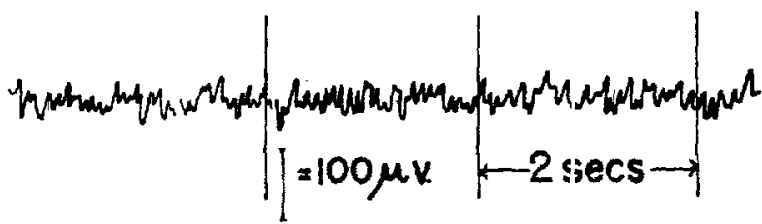

E.E.G. - Extracorporeal Circulation Venous Congestion.

Figure 3

gram became abnormal soon after the perfusion commenced and the perfusion was stopped. On a second try the pattern remamed satisfactory although the electroencephalographic recovery from the effects of the first perfusion was slow. We had no explanation for this case, but obviously there was a defect in the circulation, resulting in cerebral ischaemia. Snce changing from the "bubble oxygenator and sigma pump" to the "disc oxygenator with non-occlusive roller pump," we have encountered a few simular cases, all of which have been corrected by increasing the arterial flow. Such inadequate flows could have been overlooked had it not been for the electroencephalograph, and cerebral damage might have occurred.

In the case shown in Figure 5, after commencennent of the perfusion, the electroencephalogram rapidly detenorated to almost complete inactivity, but the patient was very pale. An obvious diagnosis of loss of arterıal flow was made and the femoral artery catheter was found to be out of the artery hidden under towels. With green drapes about the patient's head this pallor could easily have been overlooked for too long a period had it not been for the electroencephalo- 
Ist Perfusion I min.

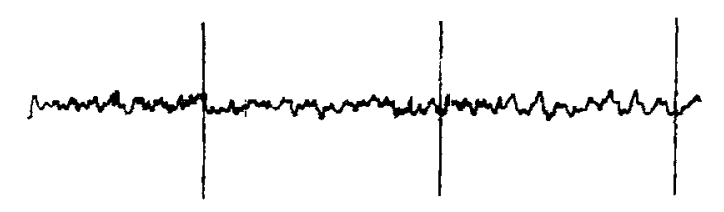

kst.Perfusion 2.5mins.

Not Congested.

Venous Pressure?

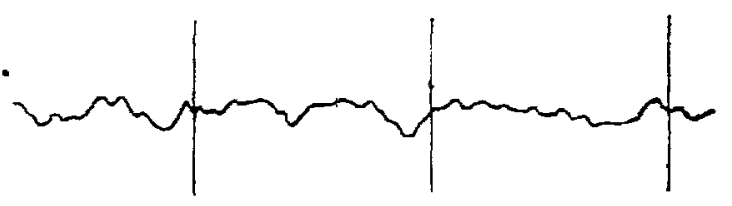

2nd Perfusion 4mins.

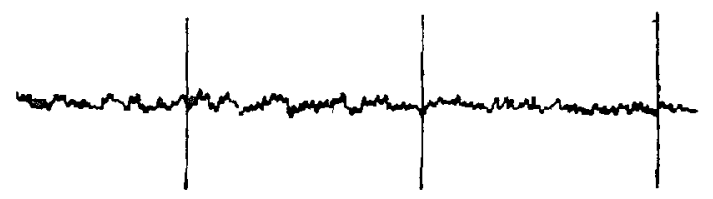

2nd Perfusion 29mins.

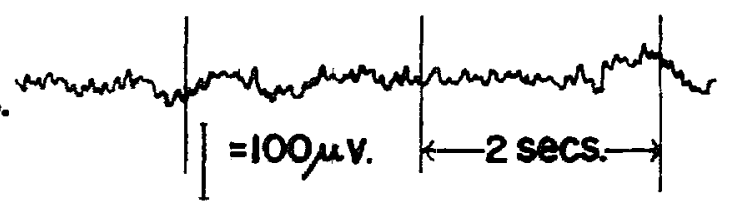

\section{E.E.G.- Extracorporeal Circulation}

FIGURE 4

Before Perfusion

Perfusion 40 secs.

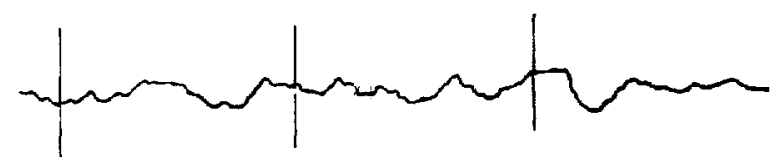

Arterial Cannula reinserted.

2nd. Perfusion 2 mins.

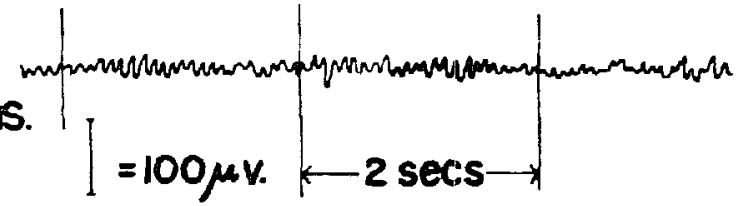

\section{E.E.G. - Extracorporeal Circulation}

\section{Arterial Cannula Lost.}


gram In this case the arterial trace was off while a blood sample was being taken Now we insist that the electroencephalogram must be running whenever the arterial tracing is not functioning.

\section{Controlled Hypotension}

Although never a popular or frequently used technique in this country many anaesthetists must on occasion use it for neuro or plastic surgery. One of the complications, especally in the older age group, is cerebral ischaemia with postoperative cerebral damage

Van Bergen (9) in a study of twelve cases reported four with changes in the electrocortıcograms. He found a marked similarity to the electroencephalogra shic patterns resulting from severe hypoxia, profound hypotension, and very ceep anaesthesia, and states that; "concervably the metabolism of the cortical cells of the cerebrum virtually has ceased as a result of anoxic anoxia, stagnant anoxia or histotoxic anoxia as the case may be."

Schallek (10), working with hypotension in dogs, found profound electroencephalographic changes which depended not only on the degree of hypotension, but also on the rate of fall. He believed that the rate of fall in some way influenced the body's abiluty to compensate by reducing the cerebrovascular resistance the more rapid the rate of pressure fall, the less the fall in cerebrovascular resistance. In the elderly arteriosclerotic patient, there may be little ability to compensate, regardless of the rate of fall. The only known simple clinical method of determining the adequacy of the cerebral curculation is the electroencephalogram

\section{Prognosis in Cerrebral Anoxia}

Bellville and Howland (11) have discussed the use of the electroencephalogram as an ard in prognosis in patients suffering from cerebral anoxia following cardiac arrest. They state that recovery without evidence of residual abnormalities is possible from almost any type or degree of electroencephalographic disorder. However, if the electroencephalographic activity has contmued flat for over four hours, there is a strong presumption that this cortical damage may not be completely reversible Even though the electroencephalogram becomes flat, if the hypoxia is corrected in less than 60 seconds, the electroencephalographic activity will return to the prehypoxic pattern promptly. There is a direct relation between the duration of the flat pattern and the time required, after correction of the hypoxia, for the electroencephalogram to return to normal.

In general Bellville states that prognosis is good if the ellectroencephalogram does not become flat after hypoxia, or if it becomes flat, the prognosis may be good if the fast activity is restored within one hour. The appearance of a "file pattern" carries a grave prognosis. Those patients in whom eventual recovery occurs show an initial tracing with considerable activity marked by moderate slow frequency waves of moderately high amplitude with superimposed higher frequency components (12). 
Figures 6, 7, and 8 show the patterns taken after cardiac arrests with severe prolonged anoxia In all cases a grave clnical prognosis was given, but the electroencephalographic prognosis was hopeful and all patients made a clinically complete recovery. Figure 9 illustrates the occurrence of a "file pattern" followng massive arterial air embolssm during open repair of a mitral incompetence. A hopeless prognosis was given and the patient died in a decerebrate state on the sixth day.
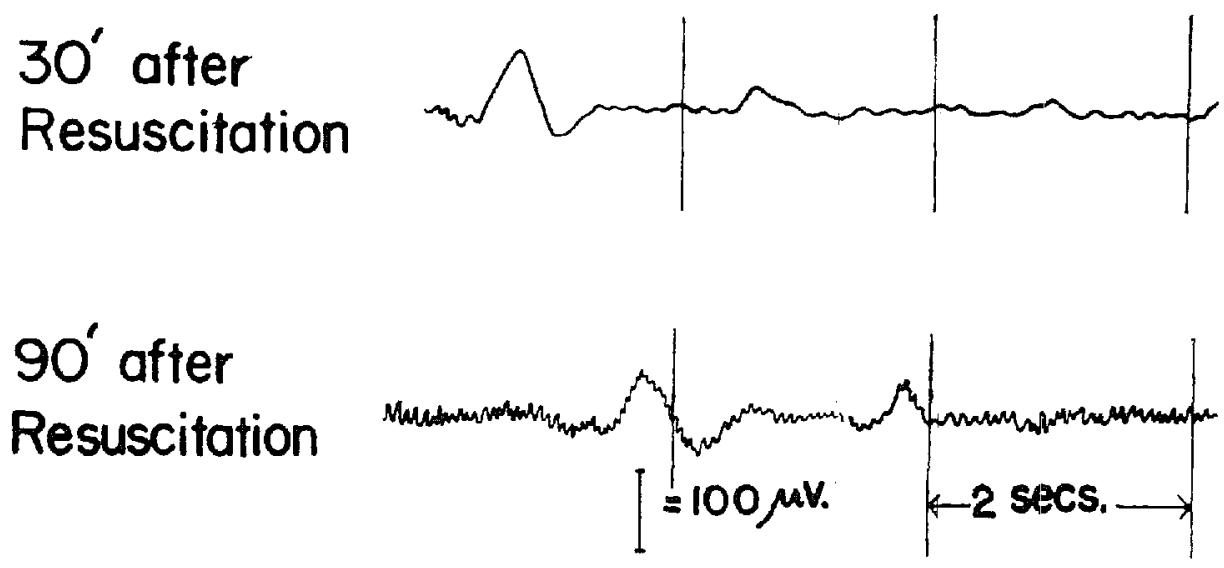

\section{Cardiac Arrest following Haemorrhage with Prolonged Hypoxia.}

Figure 6

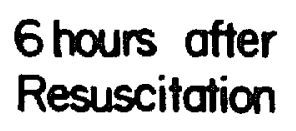

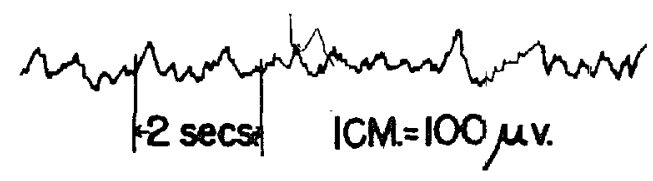

\section{Patent Ductus - severe Bronchospasm with prolonged Hypoxia and repeated (3x) \\ Cardiac Arrest.}

FigURE 7

Frequently, the question is asked when cardiac arrest has occurred; is the massage effective, should it be continued? The electroencephalogram will continue to show activity as long as massage is providing adequate cerebral circulation for brain cellular metabolism. If the electrical activity disappears, then massage is ineffective and if this state of affairs continues for several minutes then recovery may be impossible (6). 


\title{
15 hours ofter Resuscitation
}

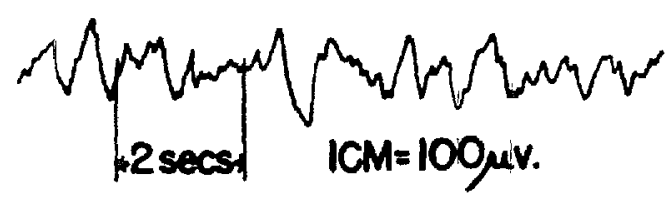

\section{Respiratory Obstruction with Cardiac Arrest.}

Figure 8

\author{
Pre Perfusion
}

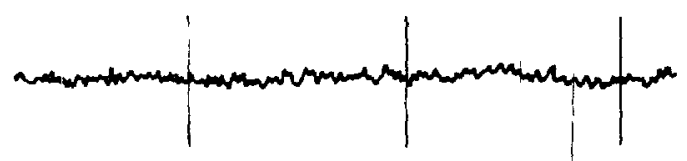

Perfusion 1Omins.

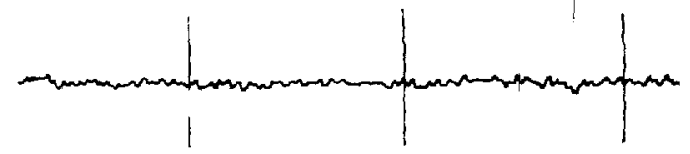

Art. Air Embolus
II.1Oam.

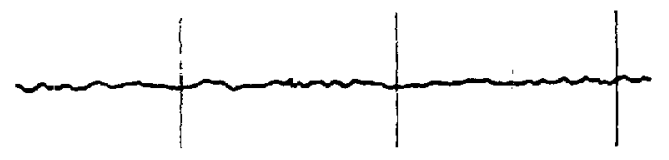

File Patterni200pm_t|

96 Hours.

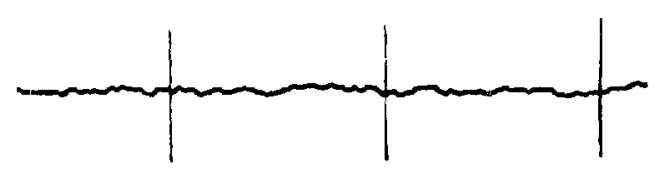

\section{Arterial Air Embolism.}

Figure 9

Teaching Aid

One of the most difficult problems in teaching the resident is to convince him that the patient is in a much deeper plane of anaesthesia than is necessary for the procedure The fear of a mobile patient and an angry surgeon is great; so the patient is frequently overdosed. This is especially so when volatile or gaseous agents are used with an apnoeic technique. Frequent spot checks with the electroencephalogram soon convince the tramee that the level of anaesthesia is much deeper than is necessary or than the clinical signs would indicate. 
There are many other possible uses for the electroencephalogram during clinical anaesthesia, to mention a few: in surgery of the carotid vessels and aorta as an indicator of high carbon dioxude levels particularly during pulmonary surgery, during mitral valvotomy when the valve is being explored and repeatedly split, and as a control during analeptic therapy for barbiturate overdose.

It is our belief that we have never been given false information when monitoring anaesthetic depth and cortical activity with the electroencephalogram and that many possible complications have been avoided. It is a valuable aid in the poor risk patient, in selected types of surgery, and as a teaching aid

\section{SUMMARY}

Because of the madequacy of the conventional signs of anaesthesia during anaesthesia with today's techniques and agents, it is suggested that the electroencephalogram is a useful guide in protecting the poor risk patient, particularly the cardiac patient, against overdose. This is especially so during the induction phase because of the "lag-phenomenon." Several examples of the value of the electroencephalogram durmg anaesthesia and extracorporeal circulation, and as a prognostic ard following cerebral hypoxia have been presented It is also suggested that the electroencephalogram is a valuable teaching and and that it is useful as a measure of the efficiency of cardiac massage during the treatment of cardiac arrest

\section{RÉSUMÉ}

A cause du manque de précision des signes conventionnels d'anesthésie au cours de l'anesthésıe qui se pratıque aujourd'hui avec les agents et les technıques modernes, l'électroencéphalogramme devient un guide précieux pour protéger les grands malades contre un surdosage éventuel de substances anesthésiques et plus particulièrement les cardiaques. Cette situation se présente surtout au cours de l'induction à cause du phénomène d'action à retardement Nous avons donné plusieurs preuves de la valeur de l'êlectroencéphalogramme durant l'anesthésie, durant la circulation extra-corporelle et comme moyen de pronostic à la suite d'hypoxie cérébrale. L'électroencéphalographie s'avère également d'un précieux secours pour l'enseıgnement de même que pour déterminer l'efficacité du massage cardiaque durant le trattement de l'arrêt cardraque.

\section{REFERENCES}

1 Guedel, A E Inhalation Anaesthesia 2nd ed New York Macmillan Co (1951)

2. Countin, R F, Brckford, R G, \& Faulconer, Albert, Jr The Classification and Significance of Electroencephalographic Patterns Produced by Nitrous-Oxide-Ether Anesthesia duning Surgical Operations Proc. Staff Meet. Mayo Clinıc 25197 (1950)

3 Faulconer, A, Jp Correlation of Concentrations of Ether in Arterial Blood with Electroencephalographic Patterns Occuring durnng Ether Oxygen and durnng NitrousOxide-Ether and Oxygen Anesthesia of Human Surgical Patients Anesthesiology 13361 (1952) 
4 Possati, S, Faulconef, A., Jr., Bickford, R. G, \& Hunter, R C Electroencephalographic Patterns during Anesthesia with Cyclopropane Correlation with Concentrations of Cyclopropane in Artenal Blood Anaesth \& Analg 32130 (1953).

5 KIERSEY, D K, Bickford, $\mathrm{R}$ G, \& Faulconer, A, JR. Electroencephalographic Patterns Produced by Thiopentol Sodium durng Surgical Operations. Description and Classification. Brit. i Anaesth 23. 141 (1951)

6 Wilson, Sheila M Electroencephalography in Relation to Anaesthesia Proc Roy Soc Med 50105 (Feb 1957).

7 Galla, S. J, Rocco Angelo, G, \& Vandam, L D Evaluation of the Traditional Signs and Stages of Anesthesia An Electroencephalographic and Clinical Study Anaesthesiology 19328 (1958)

8 Artusio, J F, Jr Ether Analgesia dunng Major Surgery J A M A. 15733 (1955)

9 Van Bergen, Frederick, H, Buckiey, Joseph J, French, Lyle A, Dobkin, Allen B, \& Brown, IAN A. Physiological Alterations Associated with Hexamethonium Induced Hypotension Anesthesiology 15507 (1954)

10 Schallex, W \& Walz, Donald Effects of Drug Induced Hypotension on the ElectroEncephalogram of the Dog Anesthesiology 15673 (1954)

11 Bellville, J Weldon, \& Howland, William S Prognosis after Severe Hypoxia in Man. Anesthesiology 18389 (1957)

12. Ghonquest, $\mathrm{Y}$ K J,, Seldon, $\mathrm{T} \mathrm{H}$, \& Faulconer, A, Jr. Cerebral Anoxia during Anaesthesia Prognostic Significance of Electroencephalographic Changes. Ann chir. gynec Fenniae 41 ]49 (1952) 